\title{
Low-tropospheric humidity inversions over Europe: spatiotemporal variability and relations to temperature inversions' occurrence
}

\author{
Angelika Palarz $^{1}$ (iD $\cdot$ Daniel Celiński-Mysław $^{1}$
}

Received: 2 January 2020 / Accepted: 27 April 2020 / Published online: 20 May 2020

(C) The Author(s) 2020

\begin{abstract}
Tropospheric humidity inversions are an important component of the Earth's climate system as well as a significant factor affecting the global radiation budget and cloud formation. Their occurrence enlarges the amount of downward longwave radiation trapped near the Earth's surface and provides moisture to maintain the top of clouds from evaporation. The aim of this paper is to examine the spatiotemporal variability of the humidity inversions over Europe. For the first time, we provide also a comprehensive analysis of relations between the humidity inversions and temperature inversions over the domain considered. The study is based on data derived from the ERA-Interim reanalysis for the period 1981-2015. We have confirmed that the temporal and spatial variability of the humidity inversions is strongly related to inversion type. The mean seasonal frequency of surface-based humidity inversions (SBHI) usually does not exceed 20\%, while the mean seasonal frequency of elevated humidity inversions (EHI) ranges from 5 to $60 \%$ depending on the region and season. On average, EHI are substantially deeper and stronger than SBHI. We found also that the low-tropospheric humidity inversions often occur simultaneously with the temperature inversions. Moderate positive correlations exist, however, only among the parameters (depth and strength) of the same inversion type, but not between the humidity inversions and the temperature inversions. Considering the links between EHI and ETI (elevated temperature inversions) parameters, slightly higher values of the Spearman's rank correlation coefficient $\left(\rho_{s}>0.50\right)$ are found between EHI base height and ETI base height. Nonetheless, the simultaneous occurrence of EHI and ETI usually fosters the intensity of both inversion types.
\end{abstract}

Keywords Humidity inversions $\cdot$ Temperature inversions $\cdot$ Water vapour $\cdot$ Air temperature $\cdot$ Cloud formation

\section{Introduction}

Atmospheric water vapour is widely known as an important component of the Earth's climate system as well as a significant factor affecting the global radiation budget and cloud formation (Kiehl and Trenberth 1997; Harrison 2000). It is also well established in the scientific literature that water vapour constitutes one of the primary greenhouse gases in the Earth's atmosphere, and thus plays an essential role in climate change feedbacks (Rind et al. 1991; Shine and Sinha 1991; Voigt and Shaw 2015). On a global scale, the amount of

Angelika Palarz

angelika.palarz@doctoral.uj.edu.pl

Daniel Celiński-Mysław

daniel.celinski-myslaw@ doctoral.uj.edu.pl

1 Department of Climatology, Jagiellonian University, Gronostajowa 7, 30-387 Kraków, Poland atmospheric water vapour decreases rapidly with increasing altitude also indicating substantial spatial and temporal variations since this amount is determined mainly by air temperature (e.g., Jackson et al. 2006; Wypych et al. 2018) There is, however, evidence that layers within which water vapour amount increases with increasing altitude also may be found. These layers are called either water vapour inversions (Devasthale et al. 2011), moisture inversions (Wypych and Bochenek 2018), or most commonly humidity inversions (e.g., Brunke et al. 2015; Naakka et al. 2018).

Previous studies have implied that humidity inversions (HI) are most likely to occur over the polar regions and socalled subtropical stratus regions (Brunke et al. 2015). Over the polar regions, $\mathrm{HI}$ are nearly permanently present on the multiple levels of the lower troposphere (Nygård et al. 2013; Nygård et al. 2014). They are most frequent in winter, while strongest in the summer melt season when a large amount of water vapour is available (Naakka et al. 2018). Comparing findings obtained for both of the polar regions, Nygård et al. (2014) concluded that the most pronounced difference 
between them is related to the range of seasonality in HI parameters - a clear seasonal cycle of HI parameters is found over the Arctic, whereas it is virtually negligible over the Antarctic. Outside the polar regions, HI are far less frequent and weaker. Their slightly higher frequency is found in the winter season over the subtropical stratus regions and much of mid-latitude Eurasia (Brunke et al. 2015). Wypych and Bochenek (2018) claimed, as an example, that frequency of the wintertime HI varies substantially across Europe peaking up to $50 \%$ over the East European Plain.

According to the most recent studies (e.g., Nygård et al. 2014; Brunke et al. 2015; Naakka et al. 2018), HI often occur simultaneously with temperature inversions (TI). Over the Arctic and Antarctic, as an example, almost half of HI are accompanied by TI (Nygård et al. 2013; Nygård et al. 2014). Wypych and Bochenek (2018) stated, in turn, that over Europe approximately $70 \%$ of surface-based HI occur simultaneously with TI. This value varies substantially from less than $60 \%$ over Western Europe to more than $90 \%$ over Eastern Europe. Also, the parameters of HI and TI are recognized to be partially linked. Over the Antarctic, a positive correlation between HI and TI depth as well as a negative correlation between HI base height and TI strength were found (Nygård et al. 2013). Over the Arctic, in turn, a positive correlation between $\mathrm{HI}$ and $\mathrm{TI}$ base height, depth, and strength as well as a negative correlation between HI base height and TI strength were identified (Nygård et al. 2014). This leads to the hypothesis that at least some part of HI and TI may develop as a result of similar mechanisms.

So far, the two most important processes underlying HI development have been described in the scientific literature, namely: (1) moisture condensation and (2) vertically differential moisture advection (e.g., Nygård et al. 2013; Nygård et al. 2014; Naakka et al. 2018). The first of these is believed to be linked to TI occurrence owing to the dependence of air temperature and saturation pressure. As reported in numerous studies (e.g., Kassomenos et al. 2014; Stryhal et al. 2017; Palarz et al. 2018), the negative radiation budget of the Earth is one of the major factors leading to the development of surface-based temperature inversions. This usually causes moisture condensation and further HI formation. Naakka et al. (2018) hypothesized that the simultaneous occurrence of HI and TI in saturated conditions might be attributed to moisture condensation, whereas the simultaneous occurrence of $\mathrm{HI}$ and relative humidity inversions is a result of the vertically differential moisture advection. Furthermore, it is known that evapotranspiration, turbulent mixing, and large-scale vertical motions may also contribute to HI development (Curry 1983; Nygård et al. 2013; Naakka et al. 2018).

Since the vertical structure of air temperature and humidity plays an essential role in determining atmospheric stability, both HI and TI seem to have great potential for further influencing the weather and climate conditions. As mentioned before, HI are believed to be an important factor affecting the Earth's radiation budget via an enhancement of the downward longwave radiation. Devasthale et al. (2011) suggested that an increase with the altitude in the water vapour amount enlarges the amount of downward longwave radiation trapped near the Earth's surface. Recent studies have also shown that HI occurrence might have substantial implications for cloud formation and maintenance (Sedlar and Tjernström 2009; Solomon et al. 2011; Sedlar et al. 2012). For example, Solomon et al. (2011) documented that the redistribution of water vapour from a humidity inversion top to its base favors the persistence of clouds. Moreover, if a cloud layer is decoupled from the Earth's surface, HI may be the only source of moisture for the cloud system (Solomon et al. 2011; Sedlar et al. 2012).

Given that a substantial part of HI and TI occurs simultaneously, their profound impact on air quality should be emphasized here as well. Generally, it is claimed that severe air pollution episodes are attributed rather to unfavorable weather conditions, mainly the long-term persistence of lowtropospheric TI, than to a sudden increase in the emission of air pollutants (e.g., Malek et al. 2006; Largeron and Staquet 2016; Hu et al. 2018). Whether HI occurrence additionally fosters, smog emergence has not been studied in detail yet. It is, however, recognized that the moist environment of the tropospheric temperature inversions favors chemical reactions in the liquid and heterogeneous phase which benefit the production of new secondary aerosols causing air pollution episodes to be more severe (Silva et al. 2007).

Despite the important role of atmospheric water vapour in the climate system, HI have received substantially less attention in the scientific literature as compared to TI. For HI investigation, the data derived from aerological soundings (Vihma et al. 2011; Nygård et al. 2013; Nygård et al. 2014), drifting sea-ice stations (Yu et al. 2019), satellite observations (Devasthale et al. 2011), and recently also multiple reanalyses (Brunke et al. 2015; Wypych and Bochenek 2018; Naakka et al. 2018) have been utilized. However, the vast majority of the studies mentioned above have focused on the polar regions, whereas in the mid-latitude regions, this kind of studies is still very rare. To the best of our knowledge, for the midlatitudes, solely Wypych and Bochenek (2018) have provided a comprehensive climatology of the vertical structure of water vapour over Europe and the Northeastern Atlantic, including an analysis of HI. This paper refers to the study of Wypych and Bochenek (2018) by providing an insight into the spatiotemporal variability of the low-tropospheric humidity inversions and their parameters over Europe. The overarching aim of this study is, however, to access the mutual relations among $\mathrm{HI}$ and TI. This is closely related to the findings demonstrated in our previous work on the surface-based and elevated temperature inversions over Europe (Palarz et al. 2018; Palarz et al. 2019). The remainder of this paper is organized as 
follows: Section 2 gives a description of the data used and outlines the methods. In section 3 , we show the results obtained and conclusions are drawn in section 4.

\section{Data and methods}

\subsection{ERA-Interim reanalysis}

As already mentioned, the study is based on the data derived from the ERA-Interim reanalysis produced by the European Centre for Medium-Range Weather Forecasts (ECMWF, Dee et al. 2011). They consist of air temperature (t), geopotential height (z), and specific humidity (q) from the entire vertical cross-section of the troposphere, i.e., from 1,000 to $100 \mathrm{hPa}$. The vertical resolution of the data varies depending on the atmospheric layer, e.g., up to $750 \mathrm{hPa}$ the records are available every $25 \mathrm{hPa}$. Note that the ERA-Interim reanalysis contains values for all of the pressure levels, which means that in high altitude regions, such as the Alps and the Carpathians, they are extrapolated below the surface. As recommended by ECMWF (Copernicus Knowledge Base 2018), we masked out the extrapolated regions by using the surface geopotential values. The horizontal resolution of the data applied is $0.75^{\circ} \times$ $0.75^{\circ}$, while the temporal resolution is $6 \mathrm{~h}-0000,0600$, 1200,1800 UTC. For brevity, however, only the results obtained for 0000 and 1200 UTC are presented in this paper. The time series spanned a period of 35 years from 1981 to 2015.

\subsection{Methods for the identification of humidity inversions and temperature inversions}

The humidity inversions were identified following the methodology applied in our previous studies on the low-tropospheric temperature inversions (Palarz et al. 2018; Palarz et al. 2019) enabling us to compare reliably the parameters of both inversion types. The definition of an inversion refers then to that reported in Kahl (1990), Wetzel and Brümmer (2011), Zhang et al. (2011), and Gilson et al. (2018). Literally, each of the vertical profiles of specific humidity (or air temperature, respectively) obtained from the ERA-Interim reanalysis was scanned upward to locate the first layer in which specific humidity (air temperature) increases with altitude. The inversion base (B) was defined as the bottom of the first layer in which the specific humidity (air temperature) increases with altitude, whereas the inversion top $(\mathrm{T})$ was defined as the bottom of the first subsequent layer in which the specific humidity (air temperature) decreases with altitude. By analogy with preceding studies (e.g., Nygård et al. 2013; Nygård et al. 2014; Stryhal et al. 2017; Czarnecka et al. 2019), we distinguished: (1) surfacebased humidity inversions (SBHI) or surface-based temperature inversions (SBTI) beginning immediately at ground level and (2) elevated humidity inversions (EHI) or elevated temperature inversions (ETI) having bases located at a higher altitude. A quantitative measure of both humidity and temperature inversions is given by three parameters, namely their frequency $(\mathrm{FQ} \%)$, depth $\left(\Delta_{z}=z_{\mathrm{T}}-z_{\mathrm{B}}\right)$, and strength $\left(\Delta_{\mathrm{q}}=\mathrm{q}_{\mathrm{T}}-\mathrm{q}_{\mathrm{B}}\right.$ and $\Delta_{\mathrm{t}}$ $=\mathrm{t}_{\mathrm{T}}-\mathrm{t}_{\mathrm{B}}$ ). In addition, for an elevated inversion its base height $\left(z_{\mathrm{B}}\right)$ was determined as well. Note that EHI and ETI parameters were calculated solely for the lower-most inversion layer, which is consistent with the methodology applied by, among others, Czarnecka et al. (2019).

Previous studies on the humidity inversions have considered various vertical ranges of the Earth's troposphere. As an example, Nygård et al. (2014) examined only humidity inversions located up to $500 \mathrm{hPa}$, whereas Wypych and Bochenek (2018) investigated humidity inversions located up to $300 \mathrm{hPa}$. In order to select the most appropriate approach, we have explored the vertical structure of specific humidity for eight grid points, whose location is shown in Fig. 1. As expected, specific humidity decreases rapidly with increasing altitude from $10.0 \mathrm{~g}$ $\mathrm{kg}^{-1}$ in summer and $3.0 \mathrm{~g} \mathrm{~kg}^{-1}$ in winter in the proximity of Earth's surface to less than $1.0 \mathrm{~g} \mathrm{~kg}^{-1}$ at the pressure level of $500 \mathrm{hPa}$ in summer and 700-600 hPa in winter (Fig. 2). Usually, above the pressure level of $400 \mathrm{hPa}$ in winter and $300 \mathrm{hPa}$ in summer, the amount of water vapour does not exceed $0.1 \mathrm{~g} \mathrm{~kg}^{-1}$ hence a reliable investigation of the humidity inversions may be limited there. Most of TI occurs, on the other hand, up to $700 \mathrm{hPa}$ (Palarz et al. 2019). Given the aim of this study, we decided therefore to restrict our analyses to inversions whose bases are located up to $3,000 \mathrm{~m}$ above ground level (AGL), which for low altitudes is comparable with the pressure level of $700 \mathrm{hPa}$.

A general view on $\mathrm{HI}$ frequency is provided on maps created separately for each humidity inversion type (SBHI; EHI), season (winter-December to February; spring - March to May; summer-June to August; autumn-September to November), and time of the day (night-time- 0000 UTC; day-time-1200 UTC). To explore potential links between $\mathrm{HI}$ and TI, we calculated the frequency of their simultaneous occurrence $\left(\operatorname{sim}_{\mathrm{F}} \mathrm{FQ}\right)$ as well as the conditional probability of TI given the occurrence of $\mathrm{HI}\left(\mathrm{CP}_{\%(\mathrm{TI} \mid \mathrm{HI})}=\mathrm{P}_{(\mathrm{TI} \cap \mathrm{HI})} / \mathrm{P}_{(\mathrm{HI})}\right)$. Furthermore, in-depth analyses of the parameters of nocturnal $\mathrm{HI}$ and their relations to TI parameters have been performed for the eight grid points mentioned before.

\section{Results}

\subsection{Spatiotemporal variability of low-tropospheric humidity inversions}

\subsubsection{Frequency of low-tropospheric humidity inversions}

As depicted in Fig. 3, SBHI are characterized by relatively low frequency $(\mathrm{FQ} \%<20 \%)$. Across mainland Europe, they occur 
Fig. 1 Distribution of the ERAInterim grid points (red dots) selected for in-depth analyses. Abbreviations for the grid points: N Northern Europe, AO1 Atlantic Ocean 1, E1 Eastern Europe 1, W Western Europe, C Central Europe, E2 Eastern Europe 2, AO2 Atlantic Ocean 2, S

Southern Europe

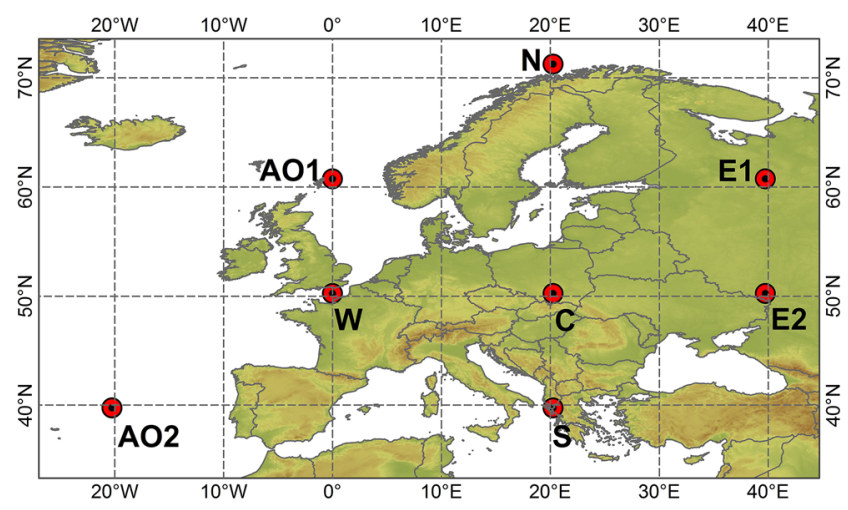

of the Fennoscandian Peninsula, in turn, wintertime SBHI are more common (FQ\% > 40\%) both at 0000 and 1200 UTC owing to the negative surface energy budget related to the occurrence of polar nights. This resembles broadly the spatiotemporal patterns of SBTI frequency (Palarz et al. 2018) suggesting that both nocturnal and wintertime SBHI are supposed to be a result of an intense radiative cooling of the Earth's surfacenegative surface energy budget leads firstly to SBTI formation and an increase of relative humidity, and in consequence to
E1

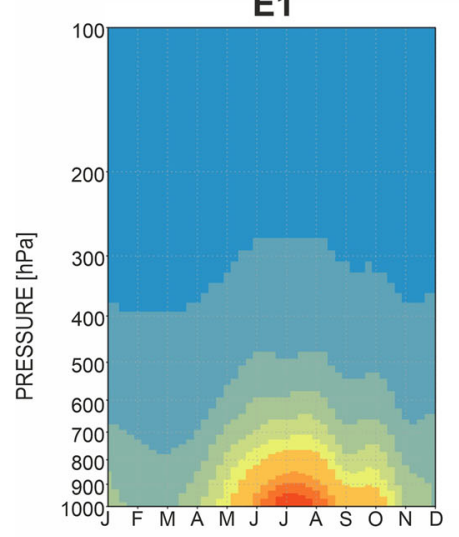

N

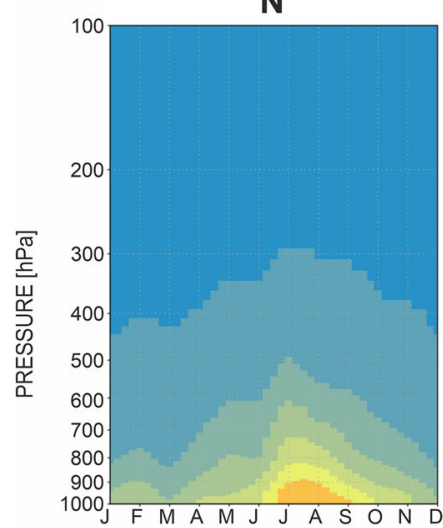

E2

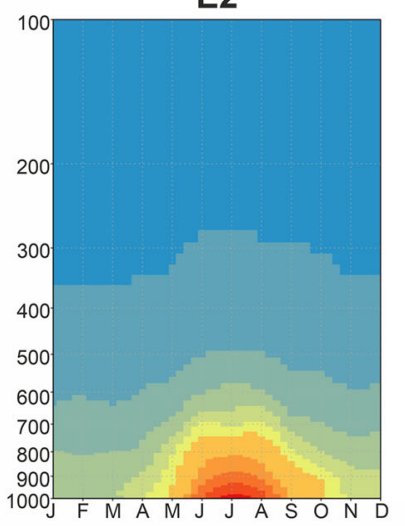

A01

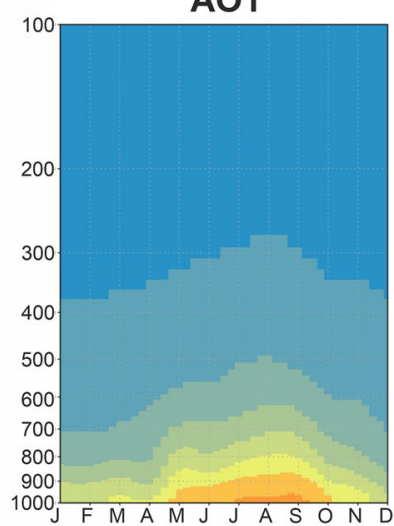

C

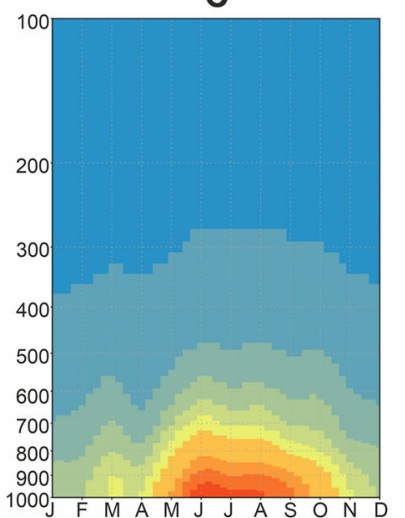

W

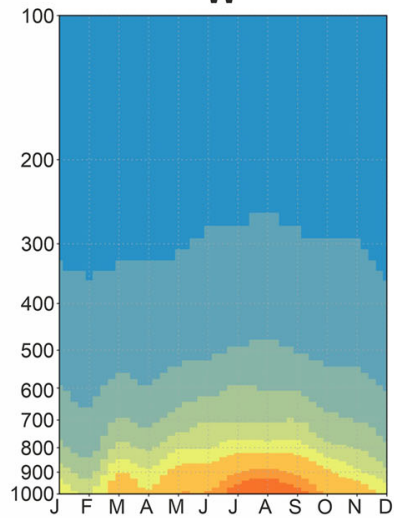

s

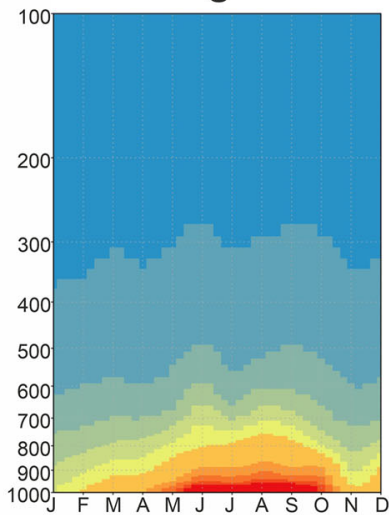

$\mathrm{AO} 2$

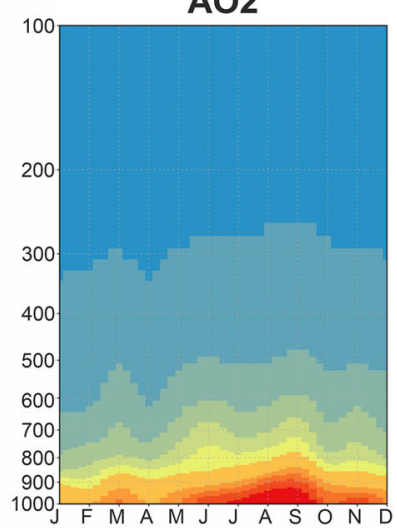

$\begin{array}{llllllllllll}0.1 & 1.0 & 2.0 & 3.0 & 4.0 & 5.0 & 6.0 & 7.0 & 8.0 & 9.0 & 10.0 & \mathrm{~g} \cdot \mathrm{kg}^{-1}\end{array}$

Fig. 2 Intra-annual variations of specific humidity $\left[\mathrm{g} \mathrm{kg}^{-1}\right]$ for night-time (0000 UTC) over the eight grid points selected. 
SBHI formation via moisture condensation (Curry 1983). Interestingly, summertime SBHI are extremely rare irrespective of the region and time of the day considered. This stands in contrast to SBTI, which attain the highest frequency in summer over most of mainland Europe, although they are rather shallow and weak then (Palarz et al. 2018). We hypothesize that summertime, mainly radiative, SBTI may not be strong or persistent enough to support moisture condensation and consequently SBHI development.

On the contrary, EHI do not exhibit substantial differences between 0000 and 1200 UTC implying that their development should be attributed to intra-annual changes in atmospheric circulation rather than processes taking place on the diurnal scale (Fig. 3). To some extent, this hypothesis might be confirmed by the location of areas of the highest EHI frequency. Considering inversions having their bases located up to $3,000 \mathrm{~m}$ AGL, its highest values $\left(\mathrm{FQ}_{\%}>50 \%\right)$ are found over Eastern Europe in winter, which correlates with the maximum activity of the semipermanent Siberian High. In the layer up to $5500 \mathrm{~m}$ AGL, in turn, a vast marine area located in the western part of the Mediterranean Sea and the eastern part of the Northeast Atlantic experiences the considerably higher frequency of
EHI $\left(\mathrm{FQ}_{\%}>50 \%\right)$ in summer, when the Azores High dominates the Atlantic Ocean reaching its greatest size and strength (not shown in this paper). This resembles broadly the spatiotemporal patterns of ETI described in our previous paper (Palarz et al. 2019) and implies that the largescale subsidence and adiabatic heating of air parcels results not only in ETI development, but also enhances moisture condensation and consequently EHI formation.

\subsubsection{Parameters of low-tropospheric humidity inversions}

The temporal and spatial variability of the low-level EHI base height, depth, and strength is presented in Fig. 4. Owing to the very low frequency of SBHI as well as a virtually negligible difference in EHI frequency between 0000 and 1200 UTC, we decided to plot solely the results obtained for nocturnal EHI. Usually, EHI tend to begin at substantially higher altitudes over the Atlantic Ocean as compared to mainland Europe (Fig. 4). Only in summer, does EHI base height reach comparable values over the land and marine areas. However, its much lower values $\left(Z_{B}<1,400 \mathrm{~m}\right.$ AGL) are typical then for the Mediterranean Sea and the northern part of the domain studied. Interestingly, higher values of summertime EHI base
$\mathrm{SBHI}$
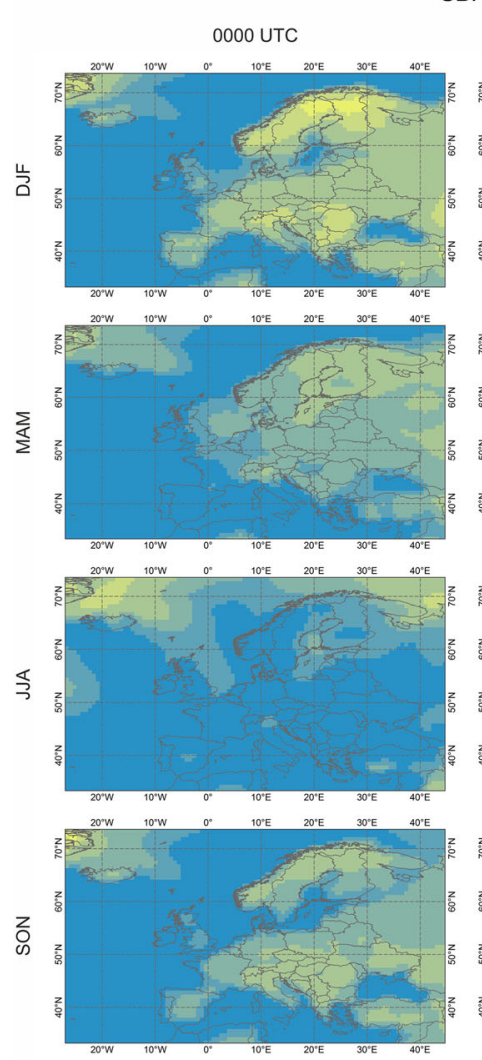

1200 UTC
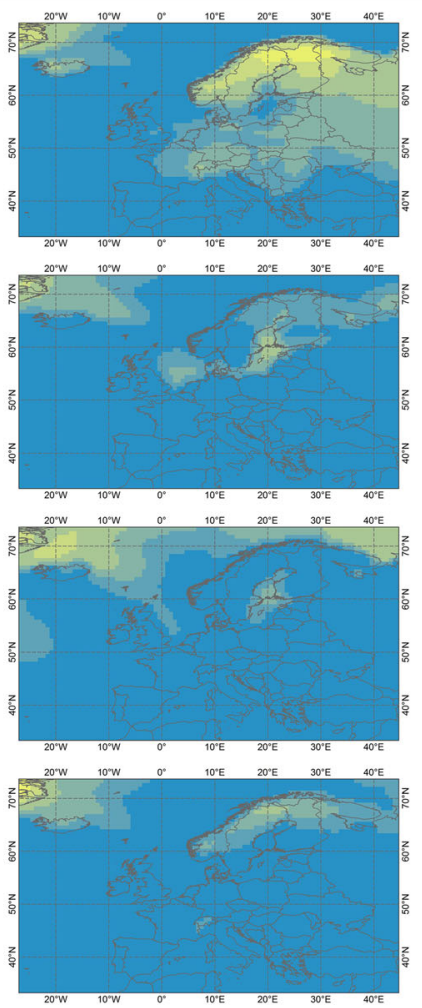

$\mathrm{EHI}$
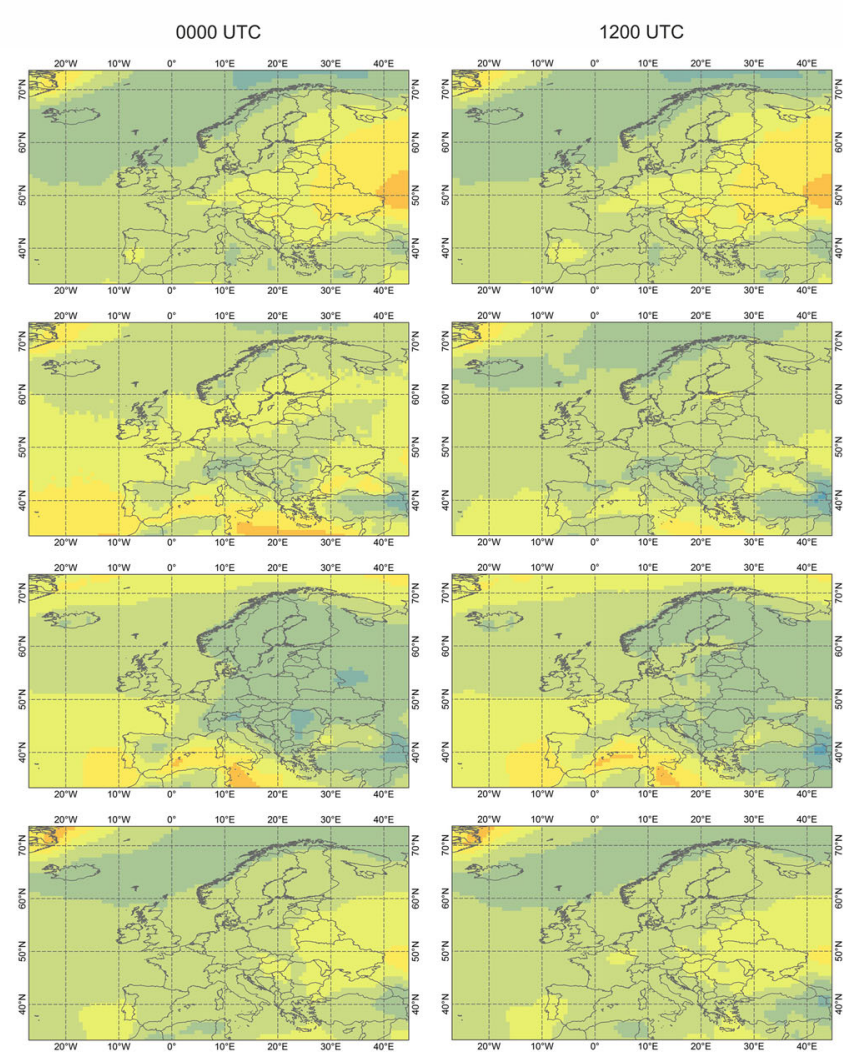

\begin{tabular}{c|ccccccccccc}
2.5 & 5 & 10 & 20 & 30 & 40 & 50 & 60 & 70 & 80 & 90 & $\%$
\end{tabular}

Fig. 3 Spatial distribution of seasonal mean frequency of SBHI and EHI calculated separately for night-time (0000 UTC) and day-time (1200 UTC) 
BASE HEIGHT
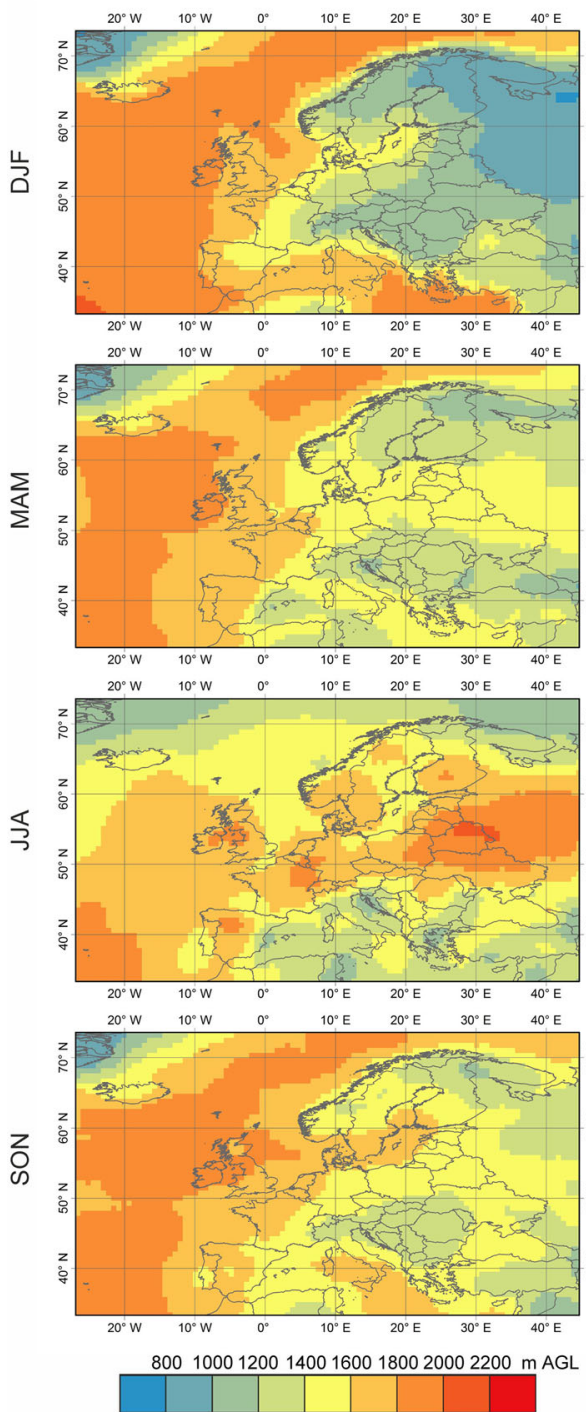

DEPTH
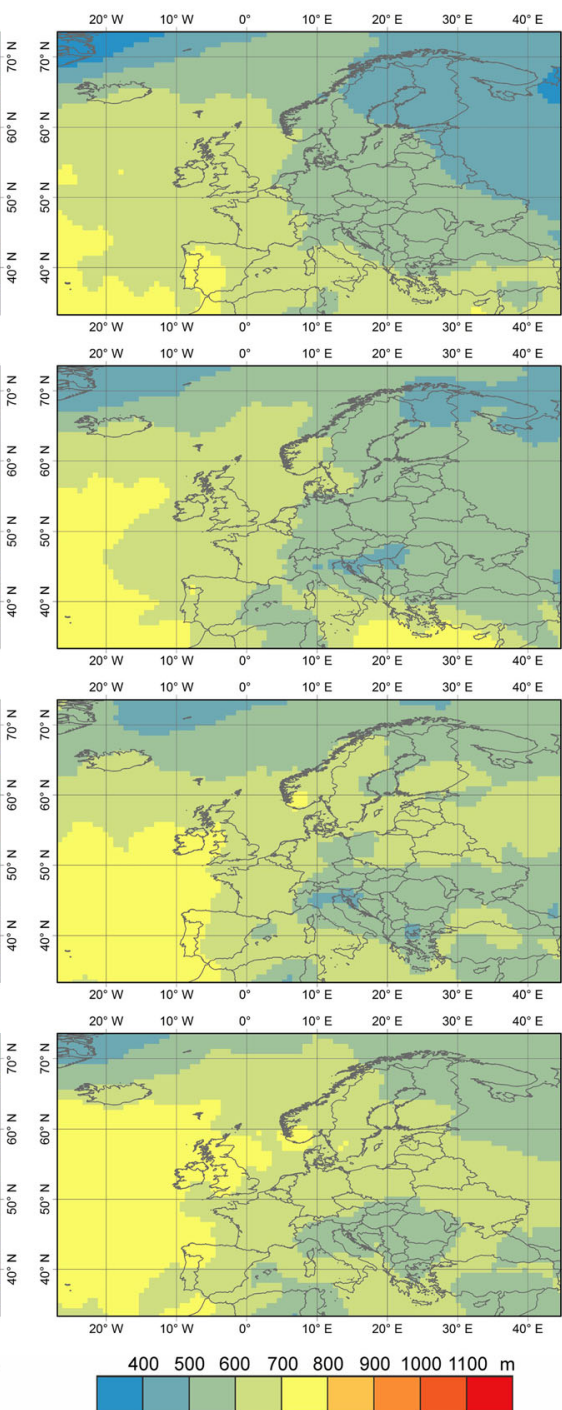

STRENGTH
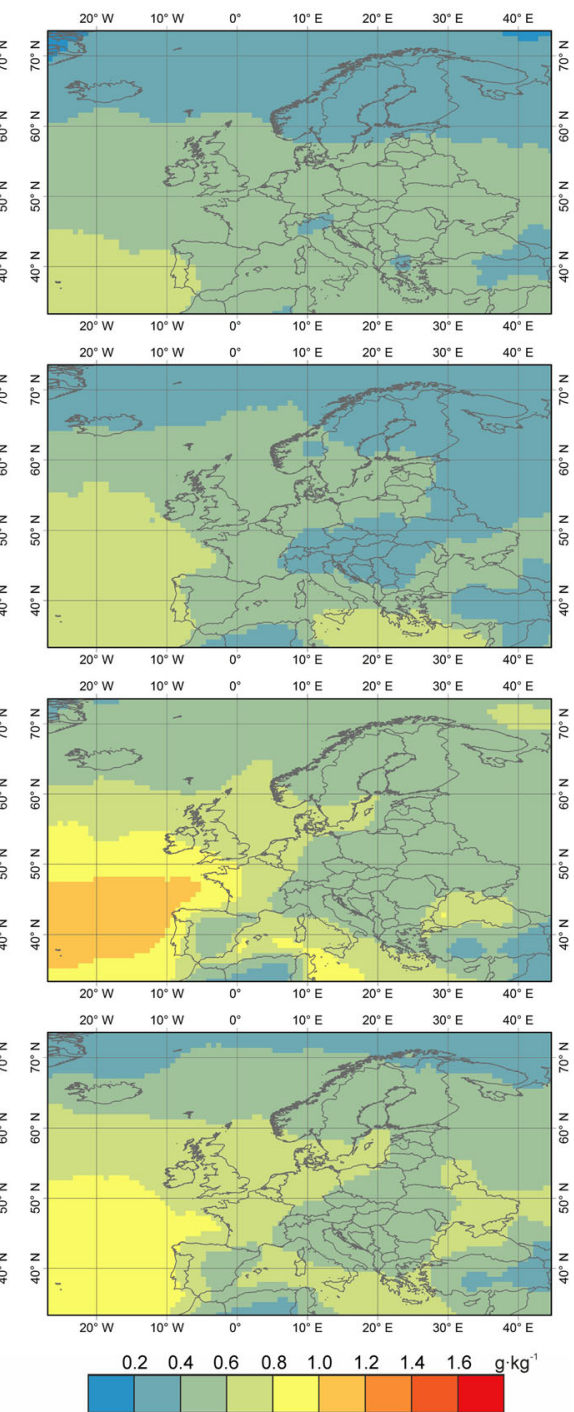

Fig. 4 Spatial distribution of seasonal mean base height, depth, and strength of EHI calculated for night-time (0000 UTC).

height correlate fairly well with a strong advection of moist air masses at the pressure level of $850 \mathrm{hPa}$ over mainland Europe discussed previously by Wypych and Bochenek (2018). On average, EHI develop at the highest altitude $\left(Z_{B}>1,800 \mathrm{~m}\right.$ AGL) in winter, spring, and autumn over extensive parts of the Atlantic Ocean, while at the lowest altitudes $\left(Z_{B}<1,000 \mathrm{~m}\right.$ AGL) in winter over Eastern Europe. Comparing to ETI, EHI tend to begin at higher altitudes (Palarz et al. 2019), which is in line with previous studies carried out for the polar regions (Nygård et al. 2013; Nygård et al. 2014).

Substantially lower intra-annual variability is demonstrated by the mean seasonal EHI depth. Its slightly higher values $\left(\Delta_{z}>\right.$ $700 \mathrm{~m}$ ) are found over the west and south-west part of the domain studied, i.e., an area encompassing the Atlantic Ocean, whereas they are lower $\left(\Delta_{z}<500 \mathrm{~m}\right)$ in winter over Northeastern Europe (Fig. 4). As illustrated in Fig. 5, which provides a rough comparison between nocturnal SBHI and
EHI parameters, EHI are significantly deeper than SBHI regardless of the grid point and season considered. Similar conclusions were drawn also in our previous paper (Palarz et al. 2019), in which we claimed that ETI tend to be deeper than SBTI. The difference between SBTI and ETI depth is, however, significantly smaller as compared to HI. Over the areas influenced by high-pressure systems, also SBTI reach relatively high values of the mean seasonal depth suggesting that anticyclonic circulation is not only an important factor supporting the subsidence and leading to ETI occurrence, but also a good precursor of the nocturnal radiation favorable for the development of deep SBTI. For SBHI, this tendency is not observed.

Similar to EHI depth, also the seasonal mean of EHI strength reaches the highest values $\left(\Delta_{q}>1.0 \mathrm{~g} \mathrm{~kg}^{-1}\right)$ in summer over the south-west part of the domain studied, i.e., the area influenced then by the Azores High (Fig. 4). Besides, this region is also the only one that experiences remarkable intra- 
annual variability. The lowest values of EHI strength $\left(\Delta_{q}<\right.$ $\left.0.2 \mathrm{~g} \mathrm{~kg}^{-1}\right)$ are found in winter and spring over the northern part of the domain studied as well as in spring over Central Europe. This seems to be linked to the general distribution of water vapour in the proximity of the Earth's surface shown in Fig. 2 as well as discussed in the paper of Wypych and Bochenek (2018), e.g., the higher value of summertime ETI strength may be explained by intensive evaporation providing a large amount of atmospheric water vapour. As demonstrated in Fig. 5, the seasonal mean strength is higher for EHI as compared to SBHI over most of the grid points considered.
On the contrary, in our previous study (Palarz et al. 2019), we claimed that SBTI are usually substantially stronger than ETI.

\subsection{Relations between low-tropospheric humidity and temperature inversions}

\subsubsection{Simultaneous occurrence of low-tropospheric humidity and temperature inversions}

As illustrated in Fig. 6, the spatiotemporal patterns of the simultaneous occurrence of the low-tropospheric humidity inversions a)
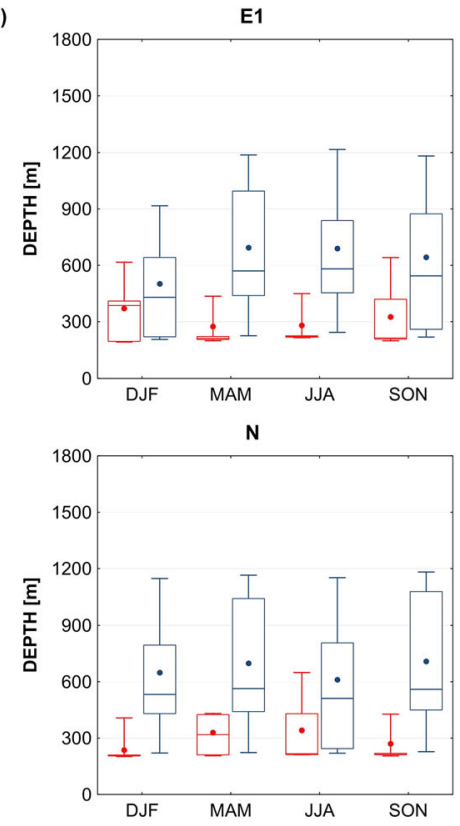

b)
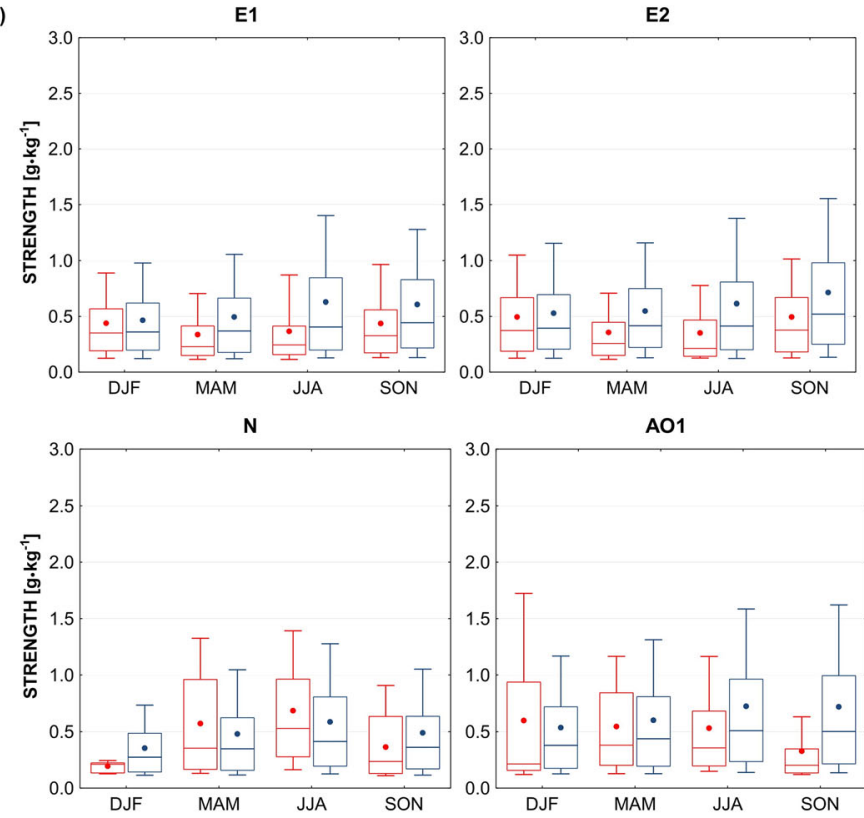

Fig. 5 Intra-annual variations of SBHI (red) and EHI (dark blue) parameters over the eight grid points selected: a depth and $\mathbf{b}$ strength. Boxes indicate the interquartile range, whereas whiskers encompass 10th and

E2

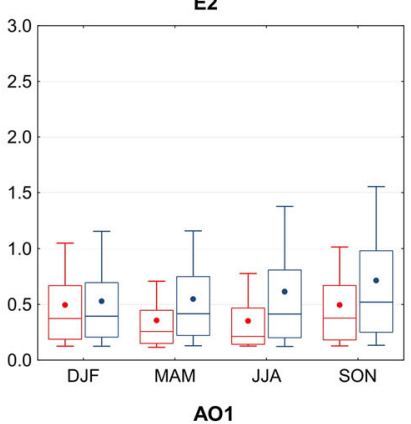

c
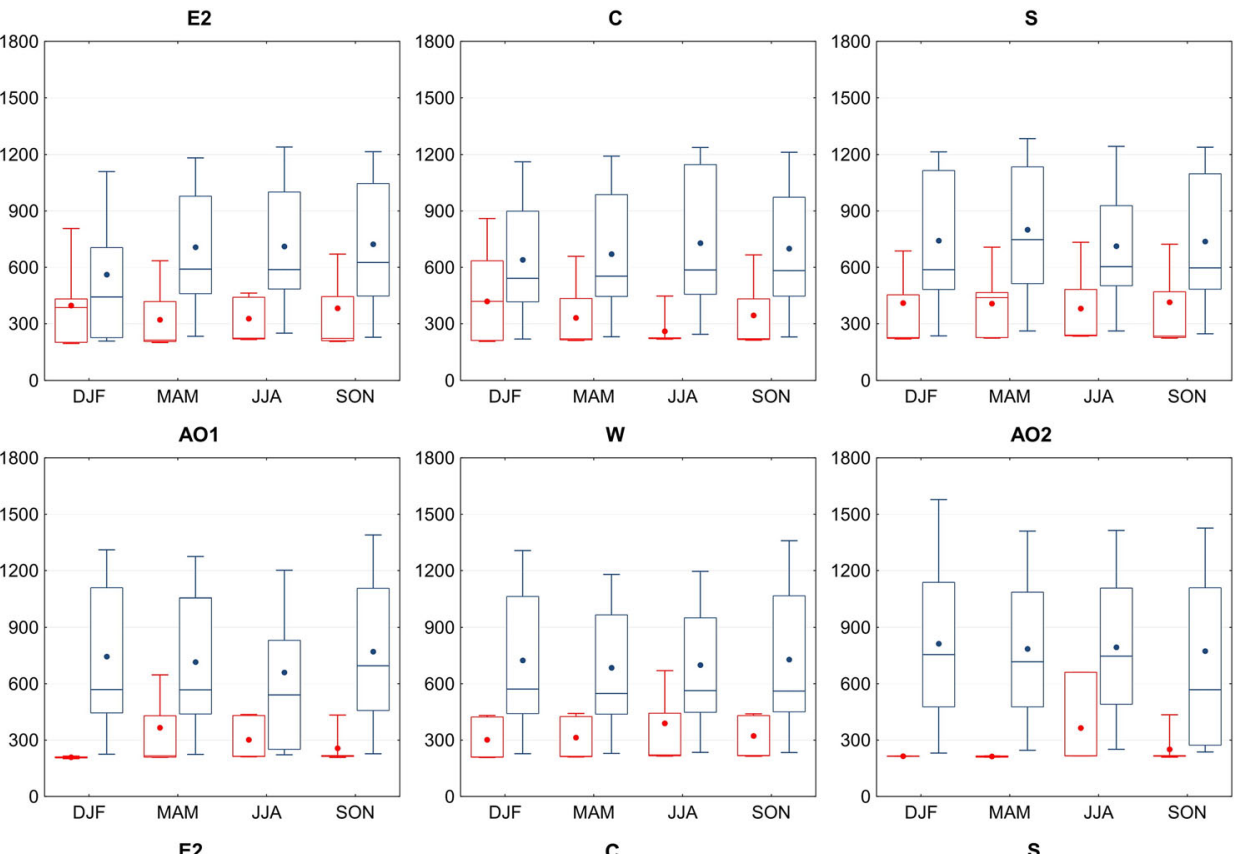

C
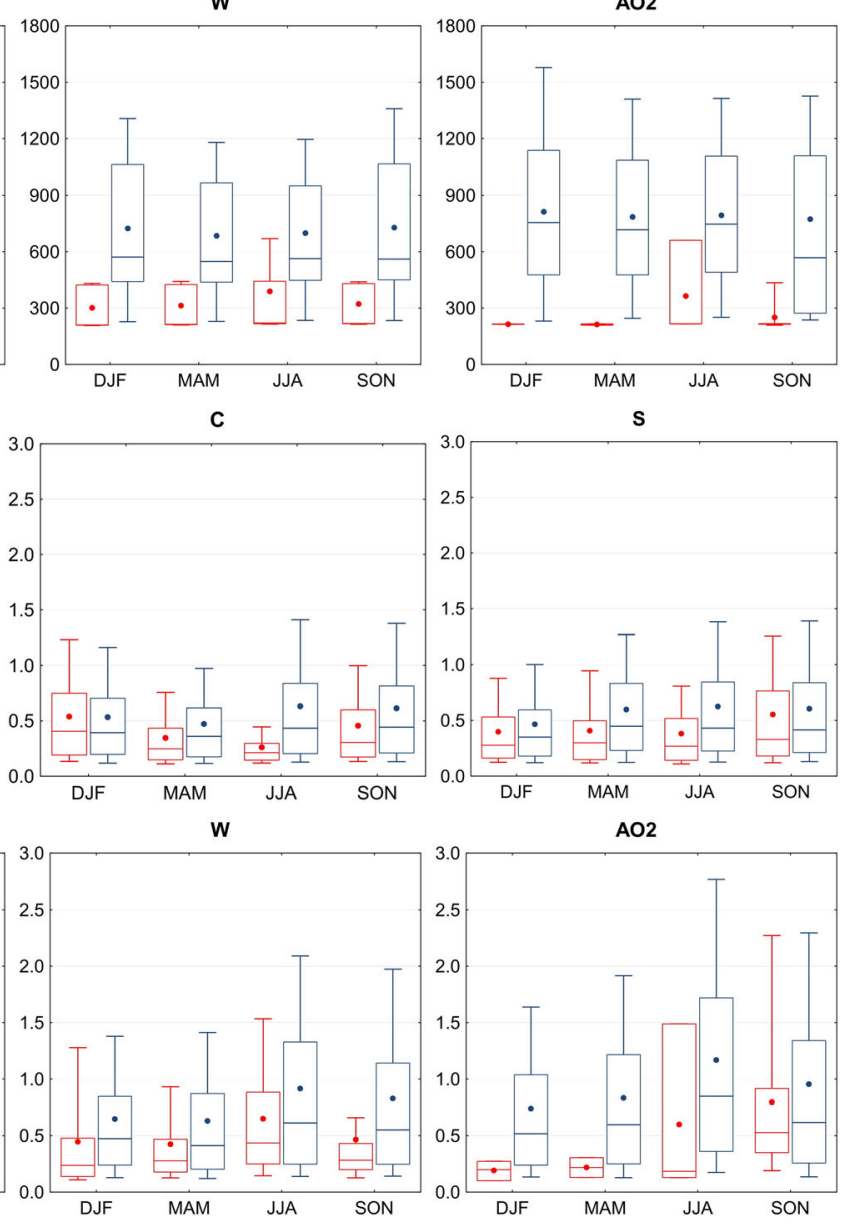

90th percentiles. The mean is displayed as a dot, whereas the median is indicated by a central solid line through the boxes. Note that solely nocturnal EHI are considered 
SBHI
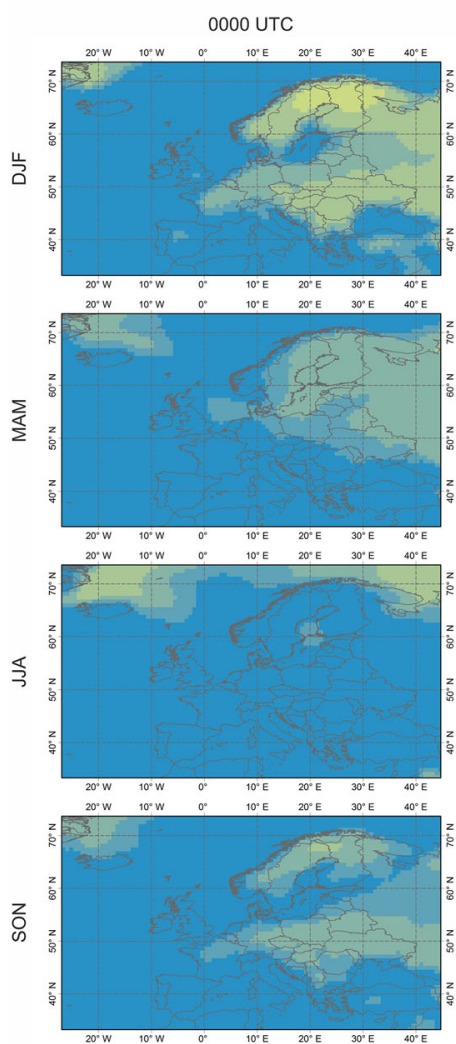

1200 UTC
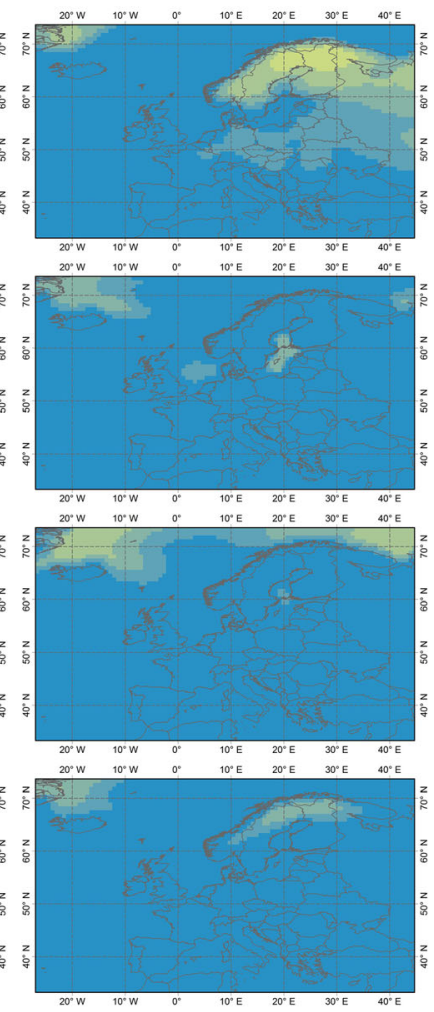

EHI
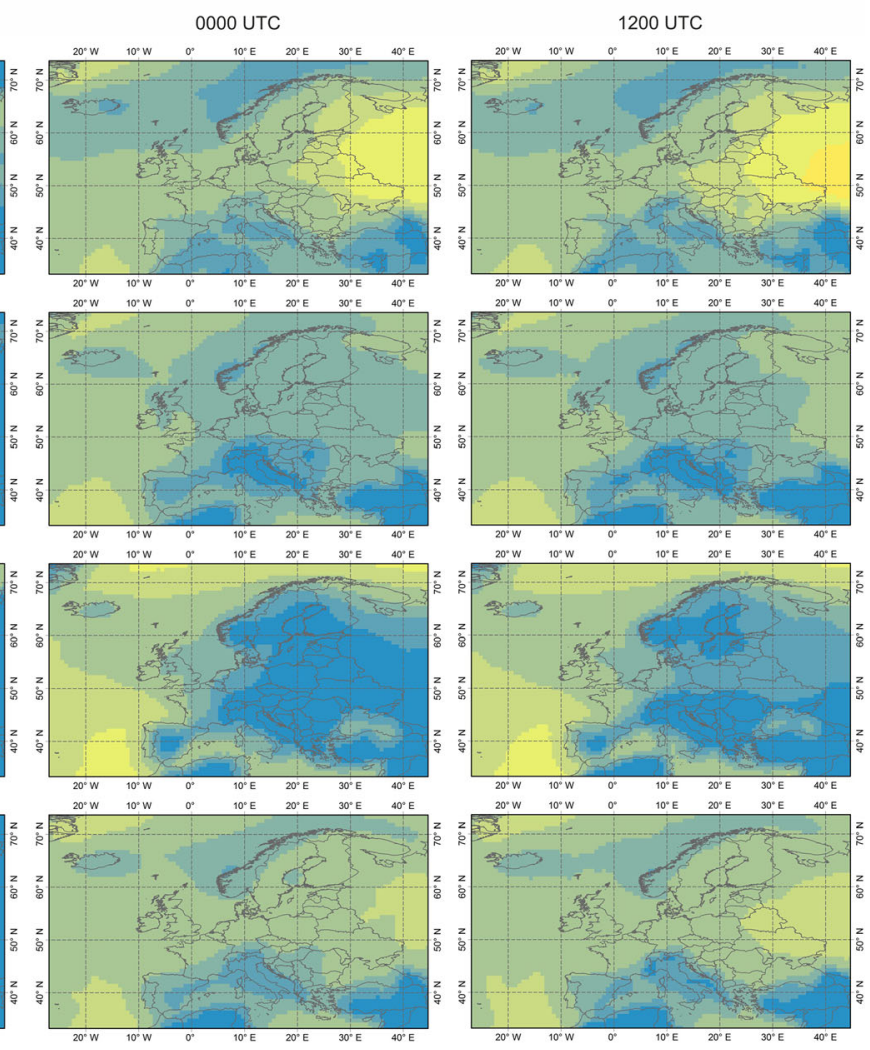

Fig. 6 Spatial distribution of seasonal mean frequency of simultaneous SBHI and SBTI as well as simultaneous EHI and ETI occurrence calculated separately for night-time (0000 UTC) and day-time (1200 UTC).

and temperature inversions resemble the variability of HI. In addition, owing to the low frequency of SBHI, the simultaneous occurrence of both surface-based inversion types is extremely rare. Across mainland Europe, it reaches a relatively high frequency $\left({ }_{\operatorname{sim}} \mathrm{FQ}_{\%}>10 \%\right)$ at night-time in winter. The highest values of the seasonal mean frequency of the simultaneous occurrence of SBHI and SBTI ( $\left.\operatorname{sim}_{\mathrm{Fi}} \mathrm{FQ}_{\%}>30 \%\right)$ are found, howev$\mathrm{er}$, in winter over the northernmost part of the Fennoscandian

Table 1 Correlation matrix of the Spearman's rank coefficient for the relations among EHI and ETI parameters over the eight grid points selectedonly statistically significant values are displayed. Note that solely nocturnal EHI and ETI are considered.

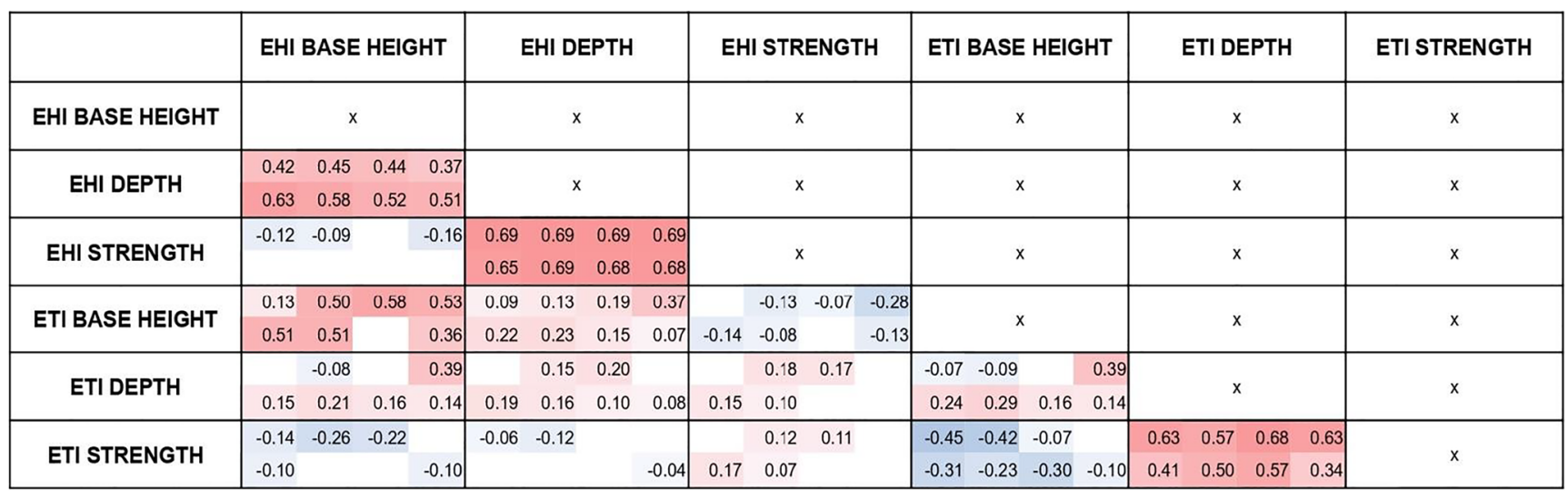

\begin{tabular}{|c|c|c|c|}
\hline E1 & E2 & C & S \\
\hline N & AO1 & W & AO2 \\
\hline
\end{tabular}


a)

E1
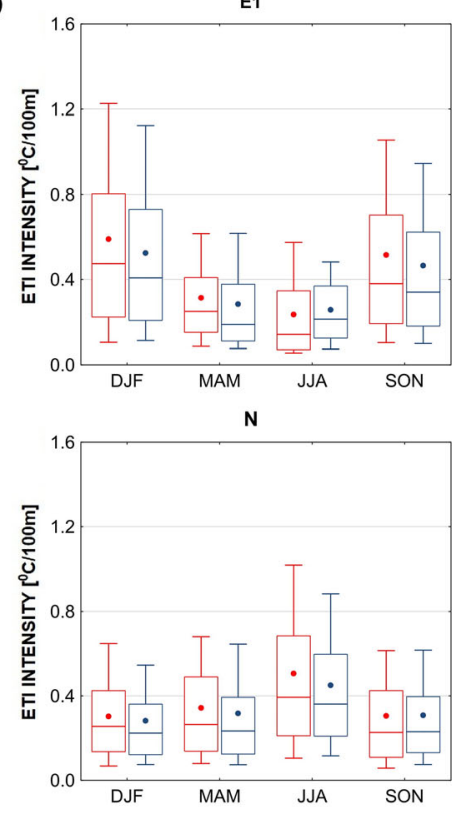

b)
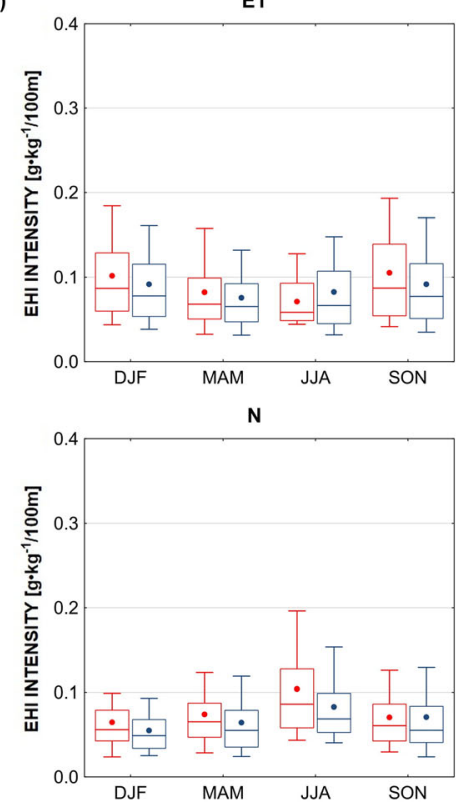

Fig. 7 Intra-annual variations of a ETI intensity given EHI occurrence (red) or non-occurrence (dark blue) and b EHI intensity given ETI occurrence (red) or non-occurrence (dark blue) over the eight grid points selected. Boxes indicate the interquartile range, whereas whiskers c

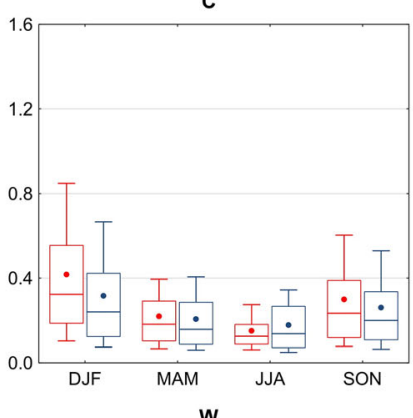

w

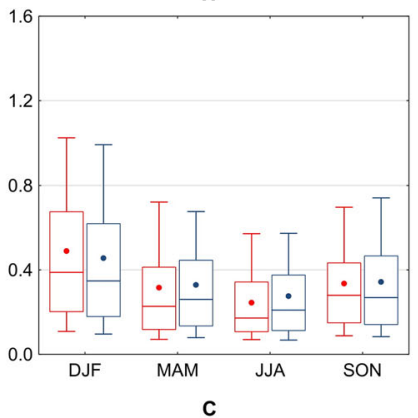

C

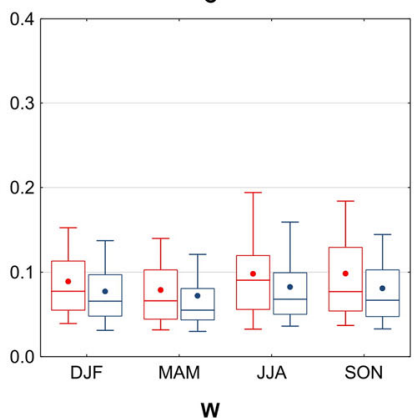

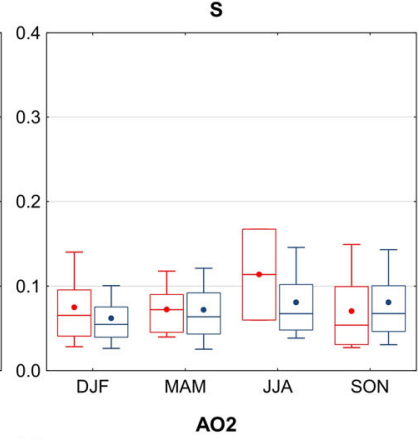

s

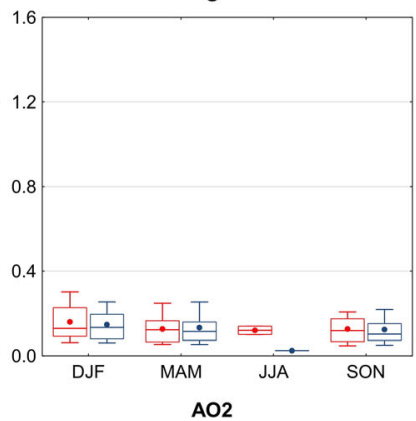

$\mathrm{AO} 2$

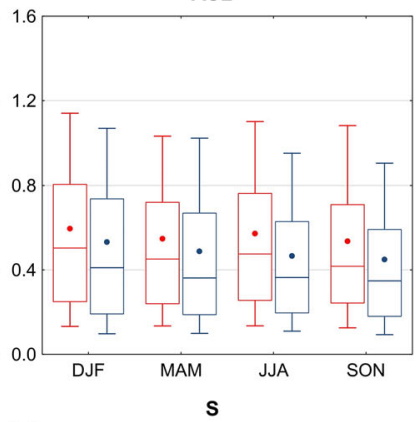

encompass 10th and 90th percentiles. The mean is displayed as a dot, whereas the median is indicated by a central solid line through the boxes. Note that solely nocturnal EHI and ETI are considered.

Peninsula both at 0000 and 1200 UTC. Considering the frequency of SBHI described in section 3.1.1, this implies that a substantial fraction of SBHI identified there is accompanied by SBTI. On the other hand, the simultaneous occurrence of the elevated inversions is most common over the areas which are under the influence of the extensive high-pressure systems - the permanent Azores High $\left({ }_{\operatorname{sim}} \mathrm{FQ}_{\%}>30 \%\right)$ and the semipermanent Siberian High $\left(\operatorname{sim}_{\mathrm{FQ}} \mathrm{F}>40 \%\right)$. The conditional probability of TI given $\mathrm{HI}$ occurrence $\left(\mathrm{CP}_{\%}\right.$ (TI $\left.\mid \mathrm{HI}\right)-$ not shown in this paper) depends strongly on the area, inversion type, season, and

time of the day. It may fluctuate from less than $10 \%$ to more than $80 \%$. This is consistent with the findings of Nygård et al. (2014), who claimed that the fraction of $\mathrm{HI}$ occurring simultaneously with TI (described here as $\mathrm{CP}_{\% \text { (TI } \mid \mathrm{HI})}$ ) is characterized by large spatial variability over the Arctic. They estimated that it varies greatly from $30 \%$ over North America to $60 \%$ over the Russian Arctic. On the other side, we found that the conditional probability of SBTI given SBHI occurrence reaches higher values $\left(\mathrm{CP}_{\%}\right.$ (SBTI $\left.\left.\mid \mathrm{SBHI}\right)>70 \%\right)$ at night-time over Eastern and Northern Europe resembling the general variability of SBTI. 
For the elevated inversions, in turn, it is highest in summer over vast areas of the Atlantic Ocean $\left(\mathrm{CP}_{\%}\right.$ (ETI | EHI) $\left.>70 \%\right)$, whereas in winter over the area influenced by the Siberian High $\left(\mathrm{CP}_{\%}\right.$ (ETI ( EHI) $70 \%)$.

\subsubsection{Parameters of low-tropospheric humidity and temperature inversions}

Following the preceding studies, we have aimed to assess the potential links among the parameters of the low-tropospheric humidity inversions and temperature inversions. By analogy with section 3.1.2, here we focus exclusively on EHI and ETI parameters. Most of them do not show linear relationships among each other, which is mainly due to their positively skewed distribution. As shown in Table 1, the Spearman's rank correlation coefficient $\left(\rho_{s}\right)$ exceeds the value of 0.60 only for the relations among the parameters of the same inversion type, i.e., EHI depth correlates positively with EHI strength, whereas ETI depth correlates positively with ETI strength. Note that for the latter relation, the Spearman's rank correlation coefficient exceeds the above-mentioned value solely for grid points located in land areas. A slightly weaker positive correlation is found also between EHI base height and EHI depth. Our results did not confirm the findings of Nygård et al. (2014), who claimed that over the Arctic, TI parameters are much more commonly correlated to each other than HI parameters are correlated to each other. Considering the links between EHI and ETI parameters, somewhat higher values of the Spearman's rank correlation coefficient $\left(\rho_{s}>0.50\right)$ are observed between EHI base height and ETI base height, however only for five over the eight grid points selected.

Figure 7 presents the intra-annual variations of ETI intensity under the condition of EHI occurrence or non-occurrence as well as EHI intensity under the condition of ETI occurrence or non-occurrence. As stated in section 3.1.2, this parameter encompasses information on both the depth and strength of the inversion layer and is used for brevity here. Despite the lack of linear relations among EHI and ETI parameters, we found that ETI intensity is typically higher under the condition of EHI occurrence as compared to EHI non-occurrence. The same has also been identified for EHI given ETI occurrence or non-occurrence, respectively. Moreover, these tendencies are usually valid also for the other parameters of the inversions, i.e., depth and strength (not shown in this paper). Similar results were obtained by Brunke at el. (2015), who stated that $\mathrm{HI}$ are stronger when TI occur. Hence, the results obtained suggest that only strong and sufficiently persistent ETI are capable of enhancing moisture condensation and leading to EHI development. Nygård et al. (2013) suggest, in turn, that when a temperature inversion is relatively weak, also other factors may be responsible for the humidity inversion's development. This issue requires, however, further investigations. Considering EHI parameters, we may assume that ETI persistence and related to them moisture condensation influences EHI parameters far more effectively than other mechanisms supporting HI formation, e.g., moisture advection.

\section{Conclusions}

In this paper, we have provided a comprehensive climatology of the low-tropospheric humidity inversions for Europe based on the ERA-Interim reanalysis. It has been proved that the temporal and spatial variability of the humidity inversions is strongly related to their types. The mean seasonal frequency of SBHI usually does not exceed $20 \%$, while the mean seasonal frequency of EHI ranges from 5 to $60 \%$ depending on the region and season. Similar to the low-tropospheric temperature inversions (Stryhal et al. 2017; Palarz et al. 2018; Czarnecka et al. 2019), SBHI frequency also shows some day-night fluctuations with the maximum at midnight. Exceptions to this are, however, the summertime SBHI that occur extremely rarely irrespective of the region and time of the day. This suggests that the summertime SBTI is not strong or persistent enough to support moisture condensation and consequently SBHI development. EHI, in turn, do not exhibit substantial differences between 0000 and 1200 UTC suggesting that their development is attributed to intra-annual changes in atmospheric circulation rather than processes taking place on the diurnal scale. To some extent, this hypothesis may be confirmed by the location of regions of the most frequent EHI development: (1) the vast marine area west of the Iberian Peninsula throughout the year and (2) Eastern Europe in winter. Both of them are located in the areas influenced by the extensive high-pressure systems, which implies that the large-scale subsidence and adiabatic heating of air parcels result not only in ETI development (Palarz et al. 2019), but also enhance moisture condensation and consequently EHI formation. Despite the discrepancies in the methodology used for HI identification, Wypych and Bochenek (2018) also found that this phenomenon occurs most frequently in winter (January) over Eastern Europe, while in summer (July) over a vast marine area located in the south-eastern part of the Northeast Atlantic. Furthermore, they identified the higher frequency of the humidity inversions over the high-altitude regions, e.g., the Alps, the Carpathians, and the Scandinavian Mountains, which relates to the variations in SBHI occurrence described in this paper. Note, however, that Wypych and Bochenek (2018) excluded from their analysis solely the pressure levels of 1000 and $975 \mathrm{hPa}$, whereas we masked out all records extrapolated below the surface level by using the surface geopotential values as recommended by ECMWF (2018). Previous studies, such as those of Devasthale et al. (2011), Nygård et al. (2014), Wypych and Bochenek (2018), have shown evidence that $\mathrm{HI}$ are more common in winter than in summer, which according to our results is valid for SBHI, but not for EHI. 
The analysis conducted revealed that EHI tend to begin at higher altitudes than ETI (Palarz et al. 2019), which is in line with previous studies carried out for the polar regions (Nygård et al. 2013; Nygård et al. 2014). The particularly high values of the mean seasonal EHI base height are found over the Atlantic Ocean throughout the year as well as over the mainland of Europe in summer. As mentioned before, the higher mean seasonal values of EHI base height in summer correlate fairly well with a strong advection of moist air masses at the pressure level of $850 \mathrm{hPa}$ over mainland Europe discussed previously by Wypych and Bochenek (2018). Substantially lower intraannual variability is demonstrated by the mean seasonal EHI depth and strength. Typically, EHI tend to reach higher values of the mean seasonal depth and strength than SBHI. On the contrary, in our previous study (Palarz et al. 2019), we claimed that SBTI are usually substantially stronger than ETI. The strongest EHI are found in summer over the marine area, which is under the influence of the Azores High, whereas the weakest in winter occur over the northern part of the domain studied. This seems to be linked to the general distribution of water vapour in the proximity of the Earth's surface shown both in Fig. 2 as well as discussed in the paper of Wypych and Bochenek (2018). Again, this is consistent with the findings of Devasthale et al. (2011) and Nygård et al. (2014), who carried out the research over the Arctic.

Across mainland Europe, the fraction of $\mathrm{HI}$ accompanied by $\mathrm{TI}$ (in this paper described here as $\mathrm{CP}_{\%}$ (TI $\mid \mathrm{HI}$ ) fluctuates from less than $10 \%$ to more than $80 \%$ depending strongly on the area, inversion type, season, and time of the day. This is similar to the findings of Nygård et al. (2014), who estimated that the fraction of HI accompanied by TI varies greatly from $30 \%$ over North America to $60 \%$ over the Russian Arctic. The values of the Spearman's rank correlation coefficient proved that moderate positive relations occur only among the parameters of the same inversion type, i.e., EHI base height correlates with EHI depth, EHI depth with EHI strength, and ETI depth with ETI strength. Our findings did not confirm the results obtained by Nygård et al. (2014), who claimed that over the Arctic TI parameters are much more commonly correlated to each other than HI parameters are correlated to each other. Despite the lack of linear relations between EHI and ETI parameters, we found that their simultaneous occurrence usually fosters the intensity as well as the depth and strength of both inversion types. Similar results were obtained by Brunke et al. (2015), who stated that $\mathrm{HI}$ are stronger when TI occur.

Although the representation of the water vapour parameters in the reanalyses may suffer from some uncertainties as compared to upper-air soundings (e.g., Serreze et al. 2012; Tsidu et al. 2014; Schröder et al. 2018), we believe that they can be successfully applied in the follow-up research on the humidity inversions. The discrepancies in the frequency of the humidity inversions identified from the reanalysis and upper-air datasets were discussed, for instance, by Brunke et al. (2015) - they claimed that their higher values found over the remote areas, such as the Arctic and Antarctic, may be due to lack of the measurements to constrain the model profiles there. On the other hand, the literature survey reveals also that even upper-air soundings may contain serious errors within the time series of the water vapor parameters (e.g., Gutman et al. 2005; Nash et al. 2006; Turner et al. 2007) - those can be excluded while quality control applied under the process of the reanalyses production. Furthermore, we would like to emphasize that although a large fraction of $\mathrm{HI}$ occurs simultaneously with TI, HI cannot be treated exclusively as a phenomenon accompanying TI. In our opinion, other mechanisms supporting HI development should also be investigated in the course of further studies. This is particularly important considering the importance of HI for the Earth's radiation budget and cloud formation.

Acknowledgments AP thanks the German Environmental Foundation, Deutsche Bundesstiftung Umwelt DBU, for supporting her as a visiting doctoral student in Germany through scholarship no. 30018/794, and the National Science Centre, Poland for funding her doctoral studies through the research project ETIUDA no. UMO-2018/28/T/ST10/00425.

Open Access This article is licensed under a Creative Commons Attribution 4.0 International License, which permits use, sharing, adaptation, distribution and reproduction in any medium or format, as long as you give appropriate credit to the original author(s) and the source, provide a link to the Creative Commons licence, and indicate if changes were made. The images or other third party material in this article are included in the article's Creative Commons licence, unless indicated otherwise in a credit line to the material. If material is not included in the article's Creative Commons licence and your intended use is not permitted by statutory regulation or exceeds the permitted use, you will need to obtain permission directly from the copyright holder. To view a copy of this licence, visit http://creativecommons.org/licenses/by/4.0/.

\section{References}

Brunke MA, Stegall ST, Zeng X (2015) A climatology of tropospheric humidity inversions in five reanalyses. Atmos Res 153:165-187. https://doi.org/10.1016/j.atmosres.2014.08.005

Copernicus Knowledge Base (2018) About pressure level data in high altitudes https://confluence.ecmwf.int/display/CKB/About+ pressure+level+data+in+high+altitudes/.

Curry J (1983) On the formation of continental polar air. J Atmos Sci 40: 2278-2292. https://doi.org/10.1175/1520-0469(1983)040<2278: OTFOCP $>2.0 . \mathrm{CO} ; 2$

Czarnecka M, Nidzgorska-Lencewicz J, Rawicki K (2019) Temporal structure of thermal inversions in Łeba (Poland). Theor Appl Climatol 136:1-13. https://doi.org/10.1007/s00704-018-2459-8

Dee DP, Uppala SM, Simmons J, Berrisford P, Poli P, Kobayashi S, Andrae U, Balmaseda M, Balsamo G, Bauer P, Bechtold P, Beljaars CM, van de Berg L, Bidlot J, Bormann N, Delsol C, Dragani R, Fuentes M, Geer J, Haimberger L, Healy SB, Hersbach H, Hólm EV, Isaksen L, Kållberg P, Köhler M, Matricardi M, Mcnally P, Monge-Sanz BM, Morcrette JJ, Park BK, Peubey C, de Rosnay P, Tavolato C, Thépaut JN, Vitart F (2011) The ERA-Interim reanalysis: Configuration and performance of the data assimilation system. Q J R Meteorol Soc 137:553-597. https://doi.org/10.1002/qj.828 
Devasthale A, Sedlar J, Tjernström M (2011) Characteristics of watervapour inversions observed over the Arctic by Atmospheric Infrared Sounder (AIRS) and radiosondes. Atmos Chem Phys 11:98139823. https://doi.org/10.5194/acp-11-9813-2011

Gilson GF, Jiskoot H, Cassano JJ, Nielsen TR (2018) RadiosondeDerived Temperature Inversions and Their Association With Fog Over 37 Melt Seasons in East Greenland. J Geophys Res Atmos 123:9571-9588. https://doi.org/10.1029/2018JD028886

Gutman SI, Facundo J, Helms D (2005). Quality control of radiosonde moisture observations. In Ninth Symposium on Integrated Observing and Assimilation Systems for Atmosphere, Oceans, and Land Surface.

Harrison RG (2000) Cloud formation and the possible significance of charge for atmospheric condensation and ice nuclei. Space Sci Rev 94:381-396. https://doi.org/10.1023/A:102670841

Hu Y, Wang S, Ning G, Zhang Y, Wang J, Shang Z (2018) A quantitative assessment of the air pollution purification effect of a super strong cold-air outbreak in January 2016 in China. Air Qual Atmos Health 11:907-923. https://doi.org/10.1007/s11869-018-0592-2

Jackson DL, Wick GA, Bates JJ (2006) Near-surface retrieval of air temperature and specific humidity using multisensor microwave satellite observations. J Geophys Res Atmos 111. https://doi.org/ 10.1029/2005JD006431

Kahl JD (1990) Characteristics of the low-level temperature inversions along the Alaska Arctic coast. Int J Climatol 10:537-548. https:// doi.org/10.1002/joc.3370100509

Kassomenos PA, Paschalidou AK, Lykoudis S, Koletsis I (2014) Temperature inversion characteristics in relation to synoptic circulation above Athens, Greece. Environ Monit Assess 186:34953502. https://doi.org/10.1007/s10661-014-3632-x

Kiehl JT, Trenberth KE (1997) Earth's annual global mean energy budget. Bull. Am Meteorol Soc 78:197-208. https://doi.org/10.1175/ 1520-0477(1997)078<0197:EAGMEB>2.0.CO;2

Largeron Y, Staquet C (2016) Persistent inversion dynamics and wintertime PM10 air pollution in Alpine valleys. Atmos Environ 135:92108. https://doi.org/10.1016/j.atmosenv.2016.03.045

Malek E, Davis T, Martin RS, Silva PJ (2006) Meteorological and environmental aspects of one of the worst national air pollution episodes (January, 2004) in Logan, Cache Valley, Utah, USA. Atmos Res 79: 108-122. https://doi.org/10.1016/j.atmosres.2005.05.003

Naakka T, Nygård T, Vihma T (2018) Arctic humidity inversions: climatology and processes. J Clim 31:3765-3787. https://doi.org/10. 1175/JCLI-D-17-0497.1

Nash J, Smout R, Oakley T, Pathack B, Kurnosenko S. (2006) The WMO intercomparison of radiosonde systems - Final Report Vacoas, Mauritius.

Nygård T, Valkonen T, Vihma T (2013) Antarctic low-tropospheric humidity inversions: 10-yr climatology. J Clim 26:5205-5219. https:// doi.org/10.1175/JCLI-D-12-00446.1

Nygård T, Valkonen T, Vihma T (2014) Characteristics of Arctic lowtropospheric humidity inversions based on radio soundings. Atmos Chem Phys 14:1959-1971. https://doi.org/10.5194/acp-14-1959-2014

Palarz A, Celiński-Mysław D, Ustrnul Z (2018) Temporal and spatial variability of surface-based inversions over Europe based on ERA-Interim reanalysis. Int J Climatol 38:158-168. https://doi.org/10.1002/joc.5167

Palarz A, Celiński-Mysław D, Ustrnul Z (2019) Temporal and spatial variability of elevated inversions over Europe based on ERAInterim reanalysis. Int J Climatol 40:1335-1347. https://doi.org/10. 1002/joc. 6271

Rind D, Chiou EW, Chu W, Larsen J, Oltmans S, Lerner J, McCormick MP, McMaster L (1991) Positive water vapour feedback in climate models confirmed by satellite data. Nature 349:500-503. https://doi. org/10.1038/349500a0

Schröder M, Lockhoff M, Fell F, Forsythe J, Trent T, Bennartz R, Borbas E, Bosilovich M, Castelli E, Hersbach H, Kachi M, Kobayashi S, Kursinki R, Loyola D, Mears C, Preusker R, Rossow WB, Saha S (2018) The GEWEX Water Vapor Assessment archive of water vapour products from satellite observations and reanalyses. Earth Syst Sci Data 10:10931117. https://doi.org/10.5194/essd-10-1093-2018

Sedlar J, Tjernström M (2009) Stratiform cloud — inversion characterization during the Arctic melt season. Boundary-Layer Meteorol 132: 455-474. https://doi.org/10.1007/s10546-009-9407-1

Sedlar J, Shupe MD, Tjernström M (2012) On the relationship between thermodynamic structure and cloud top, and its climate significance in the Arctic. J Clim 25:2374-2393. https://doi.org/10.1175/JCLID-11-00186.1

Serreze MC, Barrett AP, Stroeve J (2012) Recent changes in tropospheric water vapor over the Arctic as assessed from radiosondes and atmospheric reanalyses. J Geophys Res 117:D10104. https://doi.org/10. 1029/2011JD017421

Shine KP, Sinha A (1991) Sensitivity of the Earth's climate to heightdependent changes in the water vapour mixing ratio. Nature 354 : 382-384. https://doi.org/10.1038/354382a0

Silva PJ, Vawdrey EL, Corbett M, Erupe M (2007) Fine particle concentrations and composition during wintertime inversions in Logan, Utah, USA. Atmos Environ 41:5410-5422. https://doi.org/10. 1016/j.atmosenv.2007.02.016

Solomon A, Shupe MD, Persson POG, Morrison H (2011) Moisture and dynamical interactions maintaining decoupled Arctic mixed-phase stratocumulus in the presence of a humidity inversion. Atmos Chem Phys 11:10127-10148. https://doi.org/10.5194/acp-11-10127-2011

Stryhal J, Huth R, Sládek I (2017) Climatology of low-level temperature inversions at the Prague-Libuš aerological station. Theor Appl Climatol 127:409-420. https://doi.org/10.1007/s00704-015-1639-Z

Tsidu MG, Blumenstock T, Hase F (2014) Observations of precipitable water vapour over complex topography of Ethiopia from groundbased GPS, FTIR, radiosonde and ERA-Interim reanalysis. Atmos Meas Tech Discuss 7(9869-9915):2014-9915. https://doi.org/10. 5194/amtd-7-9869-2014

Turner DD, Clough SA, Liljegren JC, Clothiaux EE, Cady-Pereira KE, Gaustad KL (2007) Retrieving liquid water path and precipitable water vapor from the atmospheric radiation measurement (ARM) microwave radiometers. IEEE Trans Geosci Remote Sens 45: 3680-3690. https://doi.org/10.1109/TGRS.2007.903703

Vihma T, Kilpeläinen T, Manninen M, Sjöblom A, Jakobson E, Palo T, Jaagus J, Maturilli M (2011) Characteristics of temperature and humidity inversions and low-level jets over Svalbard fjords in spring. Adv Meteorol. https://doi.org/10.1155/2011/486807

Voigt A, Shaw TA (2015) Circulation response to warming shaped by radiative changes of clouds and water vapour. Nat Geosci 8:102106. https://doi.org/10.1038/ngeo2345

Wetzel C, Brümmer B (2011) An Arctic inversion climatology based on the European centre reanalysis ERA-40. Meteorol Z 20:589-600. https://doi.org/10.1127/0941-2948/2011/0295

Wypych A, Bochenek B (2018) Vertical structure of moisture content over Europe. Adv Meteorol 2018:1-13. https://doi.org/10.1155/ 2018/3940503

Wypych A, Bochenek B, Różycki M (2018) Atmospheric moisture content over Europe and the Northern Atlantic. Atmosphere 9:18. https://doi.org/10.3390/atmos9010018

Yu L, Yang Q, Zhou M, Zeng X, Lenschow DH, Wang X, Han B (2019) The intraseasonal and interannual variability of Arctic temperature and specific humidity inversions. Atmosphere 10:214. https://doi. org/10.3390/atmos 10040214

Zhang Y, Seidel DJ, Golaz JC, Deser C, Tomas RA (2011) Climatological characteristics of Arctic and Antarctic surfacebased inversion. J Clim 24:5167-5186. https://doi.org/10.1175/ 2011JCLI4004.1

Publisher's note Springer Nature remains neutral with regard to jurisdictional claims in published maps and institutional affiliations. 